\section{Marine pollution handbook}

Marine Pollution. Edited by R. Johnston. Pp. 729. (Academic: London and New York, 1977.) £23.40; \$51.

MARINE pollution texts are being published with almost monotonous regularity, and the subject is at best duplicated, but more often fragmentary and of poor perspective. The field is a complex one and calls for a multidisciplinary approach, and it is not without significance therefore that $\mathrm{Di}$ Johnston has chosen to produce a book by persuading colleagues to write chapters on various specialised aspects.

There are eight contributors to a volume of over 700 pages, with material organised into four principal sections. The first, by the editor, provides a broad brush background to the marine pollution scene, including aspects of fisheries biology and a brief review of the major categories of pollutants, their principal pathways in the marine environment and their potential effects. The second concerns a number of topics of importance to an understanding of the pollution problem, including material on dispersion in estuaries and coastal waters, on heavy metal contamination in the sea, on sewage pollution, on oil pollution and on the impact of pollution on seabirds. The third section is devoted to a review of the problems of measuring biological response; a very intractable problem in terms of the natural environment and one only showing signs of being amenable to treatment in terms of human health. The fourth and final section deals with the legal aspects of marine pollution regulation.

Marine pollution is a very emotive subject, and quite opposing views as to its significance are genuinely held by scientists of all disciplines engaged in oceanographic science. It would be surprising, therefore, if any reviewer could wholly agree with conclusions of one contributor, let alone eight. Nevertheless the book is remarkable in its attempt, particularly in the editor's first chapter, to provide an unbiased view of the subject; and the chapters by Bryan on metals and Topping on sewage are admirable and balanced treatments of their subjects, although Bryan's might have benefited from a slightly more quantitative treatment of the dynamics of metal uptake and loss in organisms.

Cowell's chapter on oil covers much familiar ground but is well presented and readable, although unfortunately marred at the end by an ambiguous statement according significance to mercury pollution. The persistence of mercury could not conceivably create a global pollution problem since manmade input would have to be maintained at present rates for periods commensuratc with the residence time of mercury in the oceans, say $10^{4} \mathrm{yr}$, before a significant increase in the worldwide concentrations of mercury in the oceans could be achieved. It is therefore misleading to state that persistence can necessarily be equated with global contamination, although it may be in surface waters if the pollutant is distributed by way of the atmosphere, as in the case of DDT.

The chapter by Bourne on seabirds and pollution makes interesting reading, and he rightly points out that vulnerability of birds at the end of marine food chains, and the conspicuous way in which dead animals are seen on the strand lines of beaches, often provide the earliest indication of unacceptable situations arising at sea.

\section{Muscular exercise}

Biomechanics and Energetics of Muscular Exercise. By Rodolfo Margaria. Pp. $\mathrm{x}+146$. (Clarendon: Oxford; Oxford University: London, 1976.) £7.

Ir is a pleasure to read a book by an expert expounding his life's work, an auto-festschrift as it were. Professor Margaria treats the reader to a feast cooked by a master chef, beginning with an historical note in which he himself appears as making a crucial contribution to the lactic acid-oxygen debt controversy. He leads us, by way of his own and his colleagues' work, through the intricacies of the sources of energy for muscular contraction, quantifying the contributions made by oxidation, glycolysis and phosphagen cleavage (the lactacid and alactic oxygen debt). There follows a very short and somewhat cryptic chapter on some of the cardiorespiratory changes in exercise. Here is the only serious attempt within the book to use SI units; the style and content make one suspect another and less thoughful hand. The third and final section is entitled "The biomechanics of human locomotion", in which there is a very clear description of how mechanical work may be measured and the interesting conclusions that may be drawn. The author holds out hope for the non-athletic that they too will be able to run at world (Earth) record speeds when the Olympics are held on the Moon.

The book reflects the character of the man; every now and then the
These, of course, are not always related to pollution.

The final chapter by Moore on legal aspects is a most useful review of the subject. Particularly welcome is the clear expression of the view that the function of marine pollution control is not to prohibit entirely the introduction of wastes to the sea, and that indeed the ability of the sea to absorb and assimilate waste is one of its most valuable resources: rather that marine pollution is part of the conflict between the need to release some contaminating materials to the sea and the desire to maximise the use of the marine environment as a source of food and for recreation and transport.

Alan Preston

Alan Preston is Deputy-Director of Fisheries Research in the Ministry of Agriculture, Fisheries and Food based at Lowestoft Laboratories, and Chairman of the UK Marine Pollution Monitoring Management Group.

complex and erudite arguments are interspersed with friendly pieces of practical advice, inviting the reader to relax his mental grip just for a moment. Nevertheless, the book is not for the faint-hearted, the skimmers or the dippers; it is closely argued and requires dedicated concentration. The mathematics, of which there is a good deal, is helpful and yet simple to follow; no-one need fear the book on that account. The author pleads for the adoption of his findings in everyday life-this unfortunately is the cri de coeur of many human physiologists! He spoils the case a little, however, by presuming his own degree of expertise in others; how many, for example, would describe his test for maximum anaerobic power as simple? In a world in which rapid communication is producing a tendency to dull uniformity it is interesting to note that schools of thought may still differ on the most practical matters-in Milan the stepping stool reigns supreme for almost the same stated reasons that the bicycle ergometer holds sway in Sweden.

To whom then would this book be useful? Most definitely for the serious and advanced student, but it cannot be unreservedly recommended as a standard text. Although one may overlook the occasional slipshod editing of text and figures, the use of the old units (calories and kilogram-metres), with never a joule or a watt, panders to middle age, prolongs our difficulties and introduces unnecessary confusion for those nearer the starting line.

Rainer Goldsmith

Rainer Goldsmith is Professor of Physiology in the University of London, UK. 